\title{
BECK Açısının Erişkin Patellar Yükseklik Ölçümünde Kullanımı
}

\author{
Erdem DEĞİRMENCI ${ }^{1}$
}

\section{ÖZ}

Amaç: Patella yükseklik ölçümünün özellikle diz çevresi patolojilerinin endikasyon ve cerrahi çeşitliliğin artması sonucu önemi artmıştır. Literatürde tarif edilen metotlar bulunmasına rağmen, günümüzde altın standart bir yöntem mevcut değildir. Özellikle pediatrik yaş grubunda referans noktalarının tam belirlenememesi nedeni ile ölçüm sonuçlarının güvenirliğinde sorunlar yaşanmaktadır. Jennifer J. Beck ve arkadaşları Blumensaat-Epiphyseal Containment of the Knee Angle (BECK) yöntemini tanımlamış ve pediatrik hasta grubunda kolay ve klinik alanda uygulanabilen güvenilir bir yöntem olduğunu belirtmişlerdir. Biz çalışmamızda bu yöntemin erişkinlerde kullanılabilirliğini araştırdık.

Gereç ve Yöntemler: Çalışmamıza dahil edilen çocuk hastaların lateral diz grafileri ölçümlerinden elde edilen BECK açıları kullanılarak sağlıklı erişkin aile bireylerinde patellar yükseklik ölçümü yapıldı. Aynı kişilerde bu ölçümleri Insall- Salvati ve Blumensaat yöntemleri kullanarak tekrarlandı ve bu 3 yöntemin ölçüm sonuçları karşılaştırıldı.

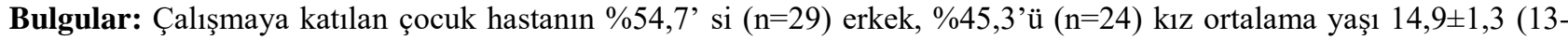

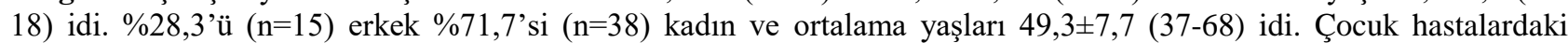
ortalama BECK açısı 46,58 $\left.\left(42,0^{\circ}-53,0^{\circ}\right) \pm 2,3^{\circ}\right)$ idi. Ortalama değer ile erişkinlerde yapılan ölçümlerde en az \%50 patellar kapsama oranı \%88,7 $(\mathrm{n}=47)$ idi. Bireysel açı değerleri ile yapılan ölçümlerde bu oran \%90,5 (n=48) olarak tespit edildi. Insall-Salvati yöntemi ile normal değer ölçüm oranı \%77,3 (41/53), anormal ölçüm \%22,6 (12) olarak saptandı. Blumensaat yöntemi ile \%62,2 (33/53) oranında normal, \%37,7 (20/53) anormal aralıkta saptandı.

Sonuç: Erişkin patellar yükseklik ölçümlerinin basit, anlaş1labilir, efektif bir yöntem ile yapılabilmesi klinik uygulamalarda büyük kolaylık sağlar. BECK yöntemi bu ölçümlerde uygulanabilecek alternatif bir yöntem olarak düşünülebilir.

Anahtar Kelimeler: Patella; diz; erişkin.

\section{Utility of the BECK Angle in Investigating Adult Patellar Height}

\begin{abstract}
Aim: The importance of patellar height measurement has increased as a result of increased indications and increased surgical technics of the knee joint pathologies. Although there are methods described in the literature, there is currently no gold standard method. Particularly in the paediatric age group, there are some problems in the reliability of the measurement results because of the difficulty in the determination of the reference points. Blumensaat-Epiphyseal Containment of the Knee Angle (BECK) method was described by the Jennifer J. Beck and et al. and it was reported that it is an easy and reliable method that can be applied surgically and clinically without requiring complicated calculations in the paediatric patient group. In our study, we investigated the usability of this method in adults.

Material and Methods: Patellar height was measured in healthy adult family members using BECK angles obtained from knee radiographs of pediatric patients enrolled in our study. The same measurements were repeated using InsallSalvati and Blumensaat methods and the results of these three methods were compared.

Results: $54.7 \%(n=29)$ of the paediatric patients who participated in the study were male and $45.3 \%(n=24)$ were female. The mean age of the patients was $14.9 \pm 1.3(13-18)$ years. $28.3 \%(n=15)$ of the adult patients were male, $71.7 \%$
\end{abstract}


$(n=38)$ were female and the mean age was 49.3 \pm 7.7 (3768) years. The mean BECK angle in paediatric patients was $46.58^{\circ}\left(42.0^{\circ}-53.0^{\circ}\right) \pm 2.3^{\circ}$. In the measurements of adults with mean value, the least $50 \%$ patellar coverage rate was $88.7 \%(n=47)$. Measurements with individual angle values, this ratio was $90.5 \%(n=48)$. Normal value measurement ratio was $77.4 \%(41 / 53)$ and abnormal measurement was $22.6 \%(12 / 53)$ by Insall-Salvati method. 62.3\% (33/53) normal and 37.7\% (20/53) abnormal ranges were determined by Blumensaat method.

Conclusion: Measurement of the adult patellar height with a simple, understandable, effective method, provides great convenience in clinical applications. The BECK method can be considered as an alternative method for these measurements.

Keywords: Patella; knee; adult.

\section{GÍRIS}

Patellar yükseklik ölçümü tarihsel olarak özellikle patellar insitabilite ve çıkıklarını araştıran bilim adamlarının ilgi konusu olmuştur $(1,2)$. Bu çalışmalarda eklem hattına göre anormal yükseklikteki patellanın kondromalazi, patella femoral artrit, dislokasyon, gibi patolojilere yol açtığının fark edilmesi ile patellar yükseklik ölçümü büyük önem kazanmıştır (3).Son yıllarda özellikle diz replasman cerrahisinde, tibial osteotomilerde ve çapraz bağ cerrahilerinde patellar yükseklik ölçümlerine sıklıkla başvurulmaktadır $(4,5)$.

Patellar yükseklik belirleme ile ilgili ilk ölçümler 1938 yılında Blumensaat (BS)'ın tarif ettiği yöntem ile başlasa da ölçüm tekniklerine zaman içinde birçok yeni metot eklenmiştir (6). Her yöntemin kendine göre avantaj ve dezavantajlarının olmasına rağmen günümüzde halen hiçbir yöntem altın standart değildir. Literatürde tanımlanan direkt ve indirekt metotlar, patellanın göreceli büyüklüğü ve onun tibia, femur veya her ikisi üzerindeki referans noktalarına olan orantılı ilişkisini ölçmektedir (7). Bu ölçüm tekniklerinde hassas, karmaşık ölçümler ve hesaplamalar gerekmektedir. Özellikle iskelet yapısı gelişmemiş çocuk hastalarda kemikleşmenin tamamlanmaması, yapılan ölçümlerdeki referans noktalarının belirlenememesi bu ölçümlerin doğrulukları ve güvenirliliği konusunda zorluklar oluşturmaktadır.

Jennifer J. Beck ve arkadaşlarının (8) yaptığı kadavra ve klinik çalışmada Blumensaat-Epiphyseal Containment of the Knee Angle (BECK) yöntemini tanımlamış ve pediatrik hasta grubunda kolay, komplike hesaplamalar gerektirmeyen, cerrahi ve klinik alanda uygulanabilen, güvenilir bir yöntem olduğu ileri sürülmüştür. $\mathrm{Bu}$ yöntemde $15-60^{\circ}$ fleksiyon aralığında çekilen lateral diz X-ray de Blumensaat çizgisi ve distal femoral epifiz çizgisi arasındaki açının patellayı kapsama oranı değerlendirilmiştir ve $\geq \% 50$ oranda kapsaması normal olarak kabul edilmiştir (Resim 1).

Biz çalışmamızda bu yöntemin erişkinlerde de kullanılabileceğini düşünerek radyografik ölçümleri yapılan pediatrik hastaların BECK açısı ile yetişkin ebeveynlerinin patella yükseklik ölçümlerini gerçekleştirdik ve bu ölçümleri tanımlanmış diğer yöntemler ile uyumunu araştırdık.

\section{GEREÇ VE YÖNTEMLER}

Çalışmamız Girişimsel Olmayan Sağlık Araştırmaları Etik Kurulu'nun 2018/206 no'lu onayı ile prospektif bir çalışma olarak planlanmıştır. Çalışmaya dahil olan tüm hastalardan bilgilendirilmiş onam formu alınmıştır. Düzce Üniversitesi Tıp Fakültesi Araştırma ve Uygulama Hastanesi Ortopedi ve Travmatoloji polikliniğinde herhangi bir diz problemi nedeni ile başvuran ve 15-60 derece fleksiyon aralığında lateral diz x-ray çekilen çocuk hastaların ölçülen BECK açısı kullanılarak sağlıklı erişkin aile bireylerinde patellar yükseklik ölçümü yapılmıştır. Yöntemin klinik kullanımının ön çalışması olarak planlanan bu çalışmada güç analizi yapılmamış olup Aralık2018-Eylül 2019 tarihleri arasında kriterlere uyan tüm hastalar dahil edilmiştir. Çalışmamıza 13-18 yaş arasında röntgenogramda femur distal epifiz hattı belirgin çocuk hastalar dahil edildi. Diz cerrahisi geçirmiş, efüzyon, kırık sekeli, nörovaskuler patolojisi olan hastalar çalışmaya dahil edilmedi. Çocuk hastalardan elde edilen BECK açıları erişkin diz lateral x-ray lerine uygulanarak patellar yükseklik ölçümü yapıldı. Aynı kişilerde patellar yükseklik ölçümleri Insall- Salvati (IS) ve BS yöntemleri kullanarak da yapıldı (Resim2) ve bu 3 yöntemin ölçüm sonuçları karşılaştırıldı. Tüm ölçümler Sectra ID-7 PACS (Sectra Uniview PACS Teknikringen 20 SE-583 30 Linköping Sweden ) sistemi üzerinden uygulandı. BECK yönteminin referans noktalarından biri olan BS çizgisi interkondiler çentik tavanından geçen çizgidir. Bu referans noktasının yüksekliği çocukluk yaş döneminde değişim gösterirken $>13$ yaş sonrasında sabit değer alır (9). Bu nedenle çalışmaya $>13$ yaş çocuklar dahil edilmiştir. Çalışmaya dahil edilen erişkin hastaların herhangi bir diz patolojisi mevcut değildi bu nedenle ölçümlerde normal yerleşimi tespit oranları değerlendirilmiştir ve diğer 2 yöntem ile karşılaştırılmıştır.

\section{İstatistiksel Analiz}

İstatistiksel analizde SPSS v.22 (SPSS/PC Inc., Chicago, IL.), programından yararlanıldı. Yöntemlerin patella yüksekliği değerlendirmesine yönelik uyumları Kappa katsayısı ile incelenmiştir. Kalitatif değişkenler sayı ve yüzde ile kantitatif değişkenler ortalama standart sapma ile sunulmuştur. İstatistiksel anlamlılık düzeyi $\% 5$ olarak belirlenmiştir.

\section{BULGULAR}

Çalışmaya katılan 53 çocuk hastanın \%54,7'si (n=29)

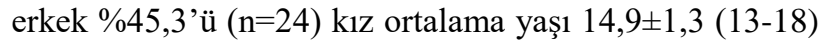
idi. Erişkin hastaların \%28,3'ü $(n=15)$ erkek \%71,7'si $(n=38)$ kadın ve ortalama yaşları 49,3 $\pm 7,7$ (37-68) idi. Çocuk hastalardaki ortalama BECK açısı $46,58^{\circ} \pm 2,3^{\circ}$ $\left(42,0^{\circ}-53,0^{\circ}\right)$ olarak saptand1. Ortalama değer ile erişkin hastalarda yapılan ölçümlerde en az \%50 patellar kapsama oranı \%88,7 $(n=47)$ idi. Bireysel açı değerleri ile yapılan ölçümlerde bu oran, \%90,5 (n= 48) olarak tespit edildi. Insall-Salvati yöntemi ile 53 dizin 41'i $(\% 77,4)$ normal değer aralığında 12'si $(\% 22,6)$ anormal aralıkta saptand. Blumensaat yöntemi ile 53 dizin 33' ü $(\% 62,3)$ normal 20'si (\%37,7) anormal aralıkta saptandı (Tablo 1). 
Tablo 1. Kalitatif sonuçların sınıflaması

\begin{tabular}{|l|c|c|c|}
\hline & \multicolumn{3}{|c|}{ Kalitatif sonuçlar (n=53) } \\
\hline Yöntem & $\begin{array}{c}\text { Patella } \\
\text { Alta }\end{array}$ & $\begin{array}{c}\text { Patella } \\
\text { Norma }\end{array}$ & $\begin{array}{c}\text { Patella } \\
\text { Baja }\end{array}$ \\
\hline $\begin{array}{l}\text { BECK } \\
\text { (ortalama) }\end{array}$ & 5 & 47 & 1 \\
\hline $\begin{array}{l}\text { BECK } \\
\text { (bireysel) }\end{array}$ & 5 & 48 & 2 \\
\hline Insall-Salvati & 8 & 41 & 4 \\
\hline Blumensaat & 13 & 33 & 7 \\
\hline
\end{tabular}

Insall-Salvati yöntemi ile normal olarak değerlendirme oranı \%77,4 (41/53), BECK yönteminin ise \%88,7(47/53) dir. Insall-Salvati ve BECK yöntemleri arasında istatistiksel olarak anlamlı bir uyum saptanmamıştır (kappa=0,477; $\mathrm{p}<0,001$ ). Toplam 53 hastada her iki yöntem de 40 hastayı normal aralıkta 5 hastayı anormal aralıkta saptamıştır. Bunun yanında 1 hasta IS yöntemi ile normal aralıkta ölçülürken BECK yöntemi anormal olarak saptamıştır. 7 hasta ise BECK yöntemi ile normal aralıkta ölçülürken IS yöntemi ile anormal aralıkta ölçülmüştür (Tablo 2).

Tablo 2. Patella yüksekliği değerlendirmesinde InsallSalvati ve BECK yönteminin uyumu

\begin{tabular}{|c|c|c|c|c|}
\hline & \multicolumn{3}{|c|}{ Insall-Salvati } \\
\hline & & Normal & Anormal & Toplam \\
\hline \multirow{3}{*}{ BECK } & Normal & 40 & 7 & 47 \\
\hline & Anormal & 1 & 5 & 6 \\
\hline & Toplam & 41 & 12 & 53 \\
\hline
\end{tabular}

Blumensaat yöntemi ile normal değer saptama oranı \%62,3 (53/33), BECK yöntemi ile 47/53 \%88,7'dir. Blumensaat ve BECK yöntemleri arasında da istatistiksel olarak anlamlı bir uyum saptanmamıştır (kappa=0,348; $\mathrm{p}=0,001$ ). Toplam 53 hastada her iki yöntem de 33 hastayı normal 6 hastayı anormal saptamıştır. Bunun yanında 4 hasta BECK yöntemi ile normal aralıkta değerlendirilirken BS yöntemi ile anormal aralıkta ölçülmüştür (Tablo 3).

Tablo 3. Patella yüksekliği değerlendirmesinde Blumensaat ve BECK yönteminin uyumu

\begin{tabular}{|c|l|c|c|c|}
\hline \multicolumn{2}{|c|}{} & \multicolumn{3}{|c|}{ Blumensaat } \\
\cline { 3 - 5 } \multicolumn{2}{|c|}{ BECK } & Normal & Anormal & Toplam \\
\cline { 2 - 5 } & Anormal & 33 & 14 & 47 \\
\cline { 2 - 5 } & Toplam & 33 & 6 & 6 \\
\hline
\end{tabular}

\section{TARTIŞMA}

Diz eklemi patolojilerinin etiyolojisinde patello-femoral ilişkinin ve patellar yüksekliğin önemli bir rol oynadığ 1 yıllar önce fark edilmiştir $(1,2)$. Bununla beraber özellikle son y1llarda diz eklemi cerrahilerinde yeni tekniklerin geliştirilmesi ve cerrahi çeşitliliğin artması ile beraber patellar yükseklik ölçümleri daha da fazla önem kazanmıştır (5).

1938 yılında Blumensaat ile başlayan ölçüm tekniklerine yıllar içinde birçok yeni yöntem eklenmiştir. Ölçüm tekniği ve kullanılan referans noktalarına göre bu yöntemler indirekt ve direkt metotlar olarak ikiye ayrilmaktadır. Direkt metotlar femur ve patellar referans noktalarını kullanırken indirekt metotlar patellar ve tibial referans noktalarını kullanır (7). Literatürde değişik ölçüm yöntemlerini karşılaştıran çeşitli çalışmalar mevcuttur ve farklı yöntemlerin üstünlükleri vurgulanmıştır (10-12). Bununla birlikte, henüz universal olarak kabul edilen "altın standart" bir yöntem yoktur (13). Dolayısı ile bir yöntemin duyarlılığını ve özgüllüğünü değerlendirmek mümkün değildir. Ancak, iyi ve ideal olduğu iddia edilen bir yöntemle arasındaki uyum incelenebilir.

Klinikte s1k kullanılan yöntemler de ise ölçümler, hesaplamalar, referans noktalarının tespiti gibi konular karmaşık işlemler gerektirmekte ve özellikle komplike diz cerrahisi gibi hızlı ve doğru ölçümlerin gerektirdiği durumlarda sorun olmaktadır. Özellikle pediatrik yaş grubunda kemik yapının tam gelişmemesi sebebi ile referans noktalarının tam belirlenememesi ölçümlerin doğruluk oranını etkilemektedir (14). Bu sebeple Jennifer J. Beck ve arkadaşları (8) yeni bir açı tarif ederek uygulanan yöntemin doğruluk oranı yüksek, pratik, basit bir yöntem olduğunu belirtmişlerdir.

$\mathrm{Bu}$ çalışmada referans alınan noktalar femur distal epifiz ve BS çizgisidir. Biz klinik izlenimlerimizde bazı erişkin hastalarda iskelet sistemi gelişimi tamamlanmış olmasına rağmen femur distal epifiz hattının tespit edilebildiği belirledik (Resim 3). Ayrıca Stijak L. ve arkadaşlarının (9) yaptığ çalışmada BS çizgisini oluşturan interkondiler femoral çentik yüksekliğinin özellikle 13 yaş ve sonrasında değişim göstermediği belirtilmiştir. Biz bu veriler 1şı̆̆ında BECK yöntemini erişkin patellar yükseklik ölçümünde kullanılabilir bir yöntem olabileceğini düşünerek çalışmamızı planladık.

Çalışmamızda bir ölçüm standardı oluşturmak amacı ile $\geq 13$ yaş çocuk hastalardan elde ettiğimiz BECK açısını birinci derece aile yakını olan erișkin hastaların patellar yükseklik ölçümlerinde kullandık. $\mathrm{Bu}$ ölçümlerin doğruluğunu karşılaştırmak içinde klinik kullanımda sık tercih edilen IS ve BS yöntemleri ile yapılan ölçümler ile karşılaştırdık.

İndirekt yöntemlerden biri olan IS metodu klinikte en s1k kullanılan ölçüm metotlarından biridir. Lateral diz grafisinde patellar tendon uzunluğu ile patellar kemik boyutunun oranının 0,8-1,2 arasında olması normal olarak tanımlanmıştır $(15,16)$. Fakat patellar kemik boyutunun değişiklik göstermesi, tuberositas tibiadaki kemik patolojileri, referans noktalarının her zaman kolay belirlenememesi işlemin zorlukları arasındadır. Yöntem ayrıca, tibial tüberkülün tibial plato altında sabit bir mesafede olduğunu varsayar. Ayrica patello femoral patolojinin tespitinde tibia gibi 3. bir referans noktasının ölçümlerde kullanılması indirekt metodlara yöneltilen başka bir eleştiridir. Yapılan bazı kadavra ve manyetik rezonans çalışmalarında IS ölçümlerinin hataları ortaya konulmuştur $(17,18)$. Dolayısı ile çeşitli modifiye IS metotları tarif edilmiştir (19).

Blumensaat metodu ise femur interkondiler çentikten tan geçen BS çizgisinin patella alt kutbuna uzaklığını ölçen direkt metotlardan biridir (6). Fakat BS çizgisinin diz fleksiyon açısından etkilenmesi, hassas ölçüm ve hesaplamalar içermesi nedeni ile ölçüm değerlerinin standardizasyonu konusunda tartışmalar mevcuttur (13). Patella yüksekliği ölçüm yöntemlerini karşılaştıran çalışmalarda, tekrarlayan ölçümlerde bireysel ve bireyler arası değişkenlikler karşılaştırılmış ve yöntemlerin 
güvenilirliği bunların sonuçlarına göre değerlendirilmiştir $(18,20)$. Bununla birlikte, tekrarlanabilirlikle güvenilir sonuç verme karşılaştırılmamalıdır. Tıbbi bir yöntemin tutarlı sonuç vermesi ile doğru sonuç vermesi apayrı kavramlardır.

Bizim çalışmamızda her bireye özgün açısal değerler elde edilse de pediatrik hastalardan elde edilen ortalama BECK açısı ile yapılan ölçümlerde de herhangi bir farklılık izlenmemiştir. Her üç yöntemin karşılaştırılmasında, normal değer saptamada en doğru ölçümün BECK yöntemi ile elde edildiği tespit edilmiştir. BECK yöntemi ölçüm sonuçlarının diğer 2 yöntem ile istatistiksel olarak uyumsuzluğunun sebebi diğer iki yöntemde anormal değer yüzdesinin BECK yöntemine göre yüksek çıkmasıdır. Insall-Salvati yönteminde referans noktalarının belirlenmesindeki zorluk ve hassas ölçüm, BS yönteminde ise ölçüm değerlerinin diz fleksiyon derecesinden etkilenmesinin bazı normal patellar yerleşimlerinin anormal olarak saptanmasına yol açtığı düşünülmektedir.

BECK yönteminin ölçümünün basit olması, cerrahi sırasında kolay ölçüm yapılabilmesi diğer yöntemlere göre temel avantajlarıdır. Fakat erişkinlerde femur distal epifizinin her zaman görülememesi, çalışmamızda kullanılan BECK açısının standart olmaması dezavantajlarımızdır. Çok daha fazla hasta sayısı ile ulaşılabilecek standart bir BECK açısı değerleri bu açının erişkin ölçümlerinde kullanılması daha doğru ve standart ölçümlerin yapılmasına yol açabilir.

$\mathrm{Bu}$ yöntemin kullanılabilir olması özellikle serebral palsi sekelli, kompleks anatomiye sahip hastaların deformite cerrahisi gibi komplike vakalarda cerrahi sırasında kolay ve efektif ölçüm yapabilme imkanı verebilir.

\section{SONUÇ}

Erişkin patellar yükseklik ölçümü diz patolojilerinin ortaya konmasında önemli bilgiler verir. $\mathrm{Bu}$ ölçümlerin basit, anlaşılabilir, efektif bir yöntem ile yapılabilmesi klinik uygulamalarda büyük kolaylık sağlar. BECK yöntemi normal değerleri saptamada ölçüm hata oranının düşük olması sebebi ile patellar yükseklik ölçümlerinde kullanılabilecek alternatif bir yöntem olarak düşünülebilir.

\section{KAYNAKLAR}

1. Aglietti P, Insall JN, Cerulli G. Patellar pain and incongruence. I: Measurements of incongruence. Clin Orthop Relat Res. 1983; (176): 217-24.

2. Ahlback S, Mattsson S. Patella alta and gonarthrosis. Acta Radiol Diagn (Stockh). 1978; 19(4): 578-84.

3. Simmons E Jr, Cameron JC. Patella alta and recurrent dislocation of the patella. Clin Orthop Relat Res. 1992; (274): 265-69.

4. Insall J, Salvati E. Patella position in the normal knee joint. Radiology. 1971; 101(1): 101-4.

5. Kesmezacar H, Erginer R, Ogut T, Seyahi A, Babacan M, Tenekecioglu Y. Evaluation of patellar height and measurement methods after valgus high tibial osteotomy. Knee Surg Sports Traumatol Arthrosc. 2005; 13(7): 539-44.

6. Blumensaat C. Die Lageabweichungen und Verrenkungen der Kniescheibe. Ergeb Chir Orthop. 1938; 31(2): 149-223.
7. Seil R, Muller B, Georg T, Kohn D, Rupp S. Reliability and interobserver variability in radiological patellar height ratios. Knee Surg Sports Traumatol Arthrosc. 2000; 8(4): 231-6.

8. Beck JJ, Boguszewskia DV, Joshia NB, Cheunga EC, Bowen RE, Oppenheima WL. A novel method for determining sagittal pediatric patellar height with the blumensaat-epiphyseal containment of the knee angle. Journal of Pediatric Orthopaedics. 2018; 27(6): 510-5.

9. Stijak L, Radonjic V, Nikolic V, Blagojevic Z, Aksic M, Filipovic B. Correlation between the morphometric parameters of the anterior cruciate ligament and the intercondylar width: gender and age differences. Knee Surg Sports Traumatol Arthrosc. 2009; 17(7): 812-7.

10. Berg EE, Mason SL, Lucas MJ. Patellar height ratios. Acomparison of four measurement methods. Am J Sports Med. 1996; 24(2): 218-21.

11. Picard F, Saragaglia D, Montbarbon E, Tourne Y, Charbel A. A morphometric study of the femoropatellar joint from lateral xray view. [Article in French] Rev Chir Orthop Reparatrice Appar Mot. 1997; 83(2): 104-11.

12. Egund N, Lundin A, Wallengren NO. The vertical position of the patella. A new radiographic method for routine use. Acta Radiol. 1988; 29(5): 555-8.

13. Seyahi A, Atalar AC, Koyuncu LO, Cinar BM, Demirhan M. Blumensaat line and patellar height. Acta Orthop Scand Traumatol Turc. 2006; 40(3): 2407.

14. Park MS, Chung CY, Lee KM, Lee SH, Choi IH. Which is the best method to determine the patellar height in children and adolescents? Clin Orthop Relat Res. 2010; 468(5): 1344-51.

15. Grelsamer RP, Proctor CS, Bazos AN. Evaluation of patellar shape in the sagittal plane: A clinical analysis. Am J Sports Med. 1994; 22(1): 61-6.

16. Burgess RC. A new method of determining patellar position. J Sports Med Phys Fitness. 1989; 29(4): 398-9.

17. Schlenzka D, Schwesinger G. The height of the patella: an anatomical study. Eur J Radiol. 1990; 11(1): 19-21.

18. Miller TT, Staron RB, Feldman F. Patellar height on sagittal MR imaging of the knee. AJR Am J Roentgenol. 1996; 167(2): 339-41.

19. Grelsamer RP, Meadows S. The modified InsallSalvati ratio for assessment of patellar height. Clin Orthop. 1992; (282): 170-6.

20. Jozwiak M, Pietrzak S. Evaluation of patella position based on radiologic and ultrasonographic examination: comparison of the diagnostic value. J Pediatr Orthop. 1998; 18(5): 679-82. 